\section{UCDNN}

LIBRARY
University of Connecticut OpenCommons@UConn

Chemistry Education Materials

Department of Chemistry

5-3-2007

\title{
Stirling's Approximation
}

Carl W. David

University of Connecticut, Carl.David@uconn.edu

Follow this and additional works at: https://opencommons.uconn.edu/chem_educ Part of the Chemistry Commons

\section{Recommended Citation}

David, Carl W., "Stirling's Approximation" (2007). Chemistry Education Materials. 49.

https://opencommons.uconn.edu/chem_educ/49 


\title{
Stirling's Approximation
}

\author{
C. W. David \\ Department of Chemistry \\ University of Connecticut \\ Storrs, Connecticut 06269-3060
}

(Dated: May 3, 2007)

\section{SYNOPSIS}

Stirling's approximation to the factorial, which is used in the Lagrange multiplier derivation of the Boltzmann distribution, is explained here.

\section{INTRODUCTION}

$\ell n(N !)$ is the starting point for this derivation, rather than $N$ factorial $(N$ !) itself.

$$
\ln N !=\ln N+\ln (N-1)+\ln (N-2) \cdots
$$

can be re-written as

$$
\ln N !=\sum_{j=0}^{j=N-1} \ln (N-j)
$$

We can picture this sum as the sum of the lengths of all the vertical lines shown in Figure 1 .

We now write this backwards:

$$
\ell n N !=\sum_{j=1}^{j=N} \ln (j)
$$

which covers the same territory. This can be seen in Figure 2.

Next, we convert this sum to an area by constucting horizontal bridges (as shown, see Figure 3) where the width of each rectangle is going to turn out to be one (1)! This means that the height and the area are synonymous!

We then have (see Figure 3):

$$
\ell n N !=\sum_{j=1}^{j=N} \ln (j)[(j+1)-j]
$$

as an area, and we rewrite this as

$$
\ln N !=\left[\operatorname{sum}_{j=1}^{j=N} \ln (j)\right] \Delta j
$$

preparatory to making the histogram to continuous func-

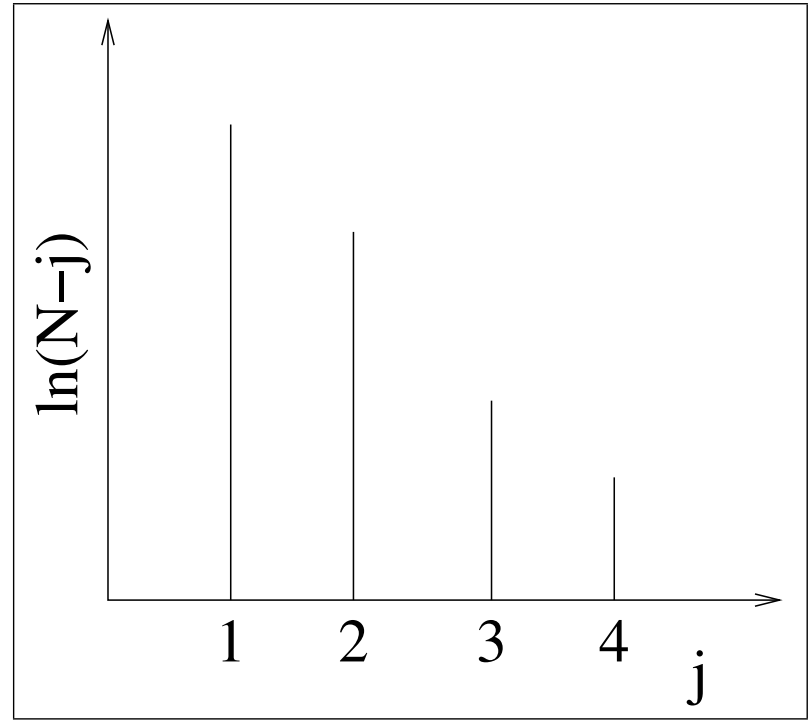

FIG. 1: The logarithmic factorial sum, shown explicitly.

tional area transformation taught in first year calculus. We then have

$$
\ell n N !=\int_{j=1}^{j=N} \ln (j) \delta j
$$

which is trivially integrable to give

$$
\ell n N !=\left.(j \ell n j-j)\right|_{j=1} ^{j=N}
$$

which evaluates to

$$
\ell n N !=N \ell n N-N-(1 \ell n 1-1)
$$

which is, in the limit $\mathrm{N}$ much larger than 1

$$
\ell n N !=N \ell n N-N
$$




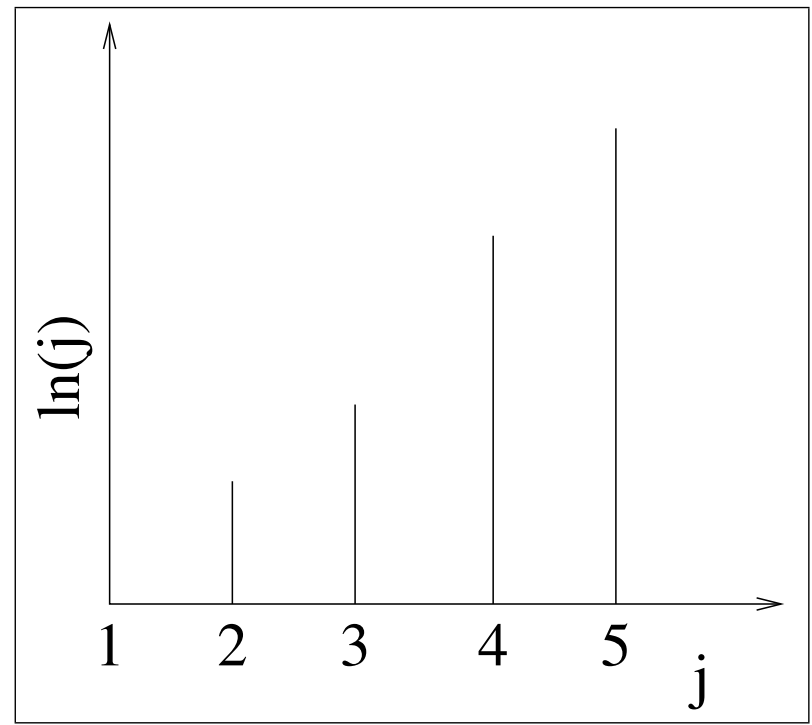

FIG. 2: The logarithmic factorial sum, reversed.

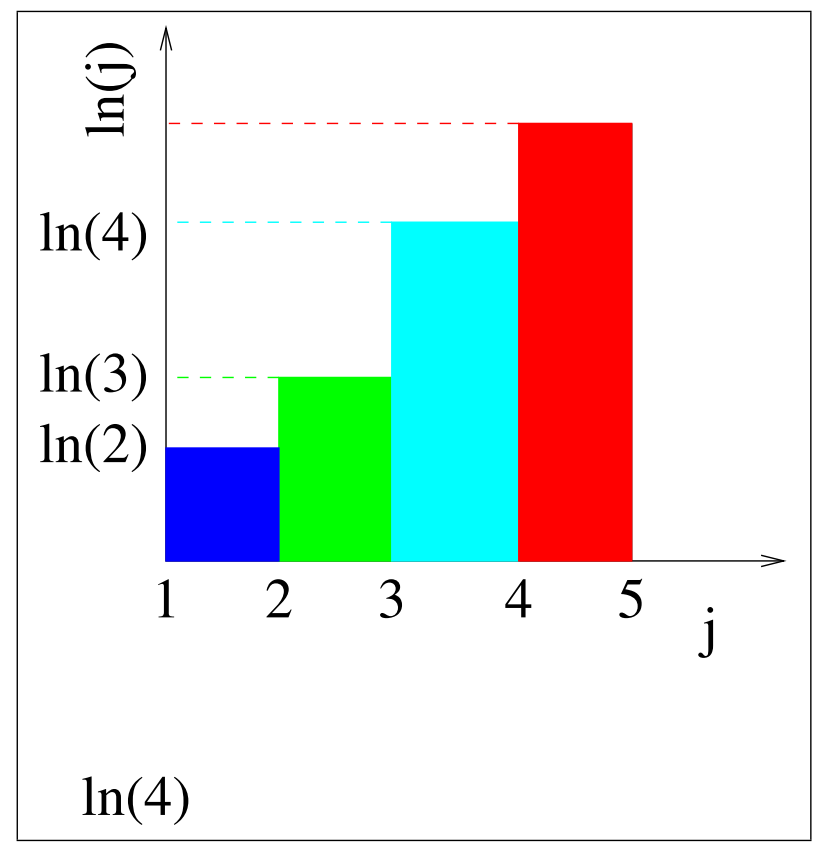

FIG. 3: The logarithmic factorial sum, converted to a histogram. 